\title{
EVOKED RESPONSES TO SINUSOIDALLY MODULATED SOUND IN UNANAESTHETIZED DOGS
}

\author{
A. M. Tielen, A. Kamp, F. H. Lopes da Silva ${ }^{1}$, J. P. Reneau ${ }^{1}$ and W. Storm van Leeuwen \\ Brain Research Group, Institute of Medical Physics TNO, Utrecht (The Netherlands)
}

(Accepted for publication: July 22, 1968)

In recent years the investigation of auditory evoked potentials has acquired a place in electrophysiology mainly as a method to obtain objective measurements of hearing function. Most studies in this field were carried out with clicks and with tone and noise bursts.

The clicks have the disadvantage that the evoked responses recorded from the scalp may have myogenic components (Bickford et al. 1964). The evoked response transients can be decreased by using tone or noise bursts with a trapezoidal envelope (Rapin et al. 1966); in these studies clear relations between tone frequency or intensity and evoked response amplitude were obtained. The click repetition rate was also shown to affect the evoked responses recorded from the cat (Teas and Kiang 1964).

We thought that it might be useful to apply another type of stimulation for exploring the auditory pathways under steady state conditions, for which purpose amplitude-modulated sound was used. It has been shown that responses produced by this form of stimulation can be recorded from the auditory cortex (AC) in anaesthetized cats (Whitfield 1953, 1957; Goldstein et al. 1959). These authors showed in cats the presence of neural activity at the auditory cortex which followed the periodicity of the stimulation at low modulation rates.

In our investigations we have treated amplitude-modulated sound in general terms. As carrier we used a sine wave of $4000 \mathrm{c} / \mathrm{sec}$ or bandlimited noise, as modulating signal sine waves at

\footnotetext{
${ }^{1}$ During a part of the period in which the reported experiments were conducted F. H. Lopes da Silva had a Gulbenkian Foundation Scholarship and J. P. Reneau a Special Fellowship (NINDB-EP 1F 11 NB 11 46-01).
}

various frequencies. Several modulation depths were applied and most experiments were carried out with the same average intensity, in a few cases, however, the latter was changed also.

To avoid any influence of anaesthetics the experiments were carried out on animals with chronically indwelling electrodes. This has, moreover, the advantage that the results can be compared more readily with data obtained in humans.

\section{METHODS AND MATERIAL}

The investigations were carried out in two dogs (German boxers), over a time course of about 1 year. Both dogs, about 2 years old, had chronically indwelling electrodes in various brain structures. (Preliminary non-systematic investigations were carried out in two other dogs. These investigations revealed no data essentially at variance with the present ones and thus are not further considered). The electrodes consisted of stainless steel wires of $100 \mu$ diameter, insulated except for $1 \mathrm{~mm}$ at the tip. The electrode positions were checked histologically.

\section{Electrode positions}

Two electrodes, E1 and E2, were placed in the inferior colliculus. Four cortical electrodes were situated as follows. E3 in the posterior sylvian gyrus and the other three E4, E5 and E6 were in the ectosylvian gyrus; i.e., in the anterior, medial and posterior parts.

\section{Sinusoidally amplitude-modulated sound arrange- ment}

The carrier signal, sine wave or noise, and

Electroenceph. clin. Neurophysiol., 1969, 26: 381-394 


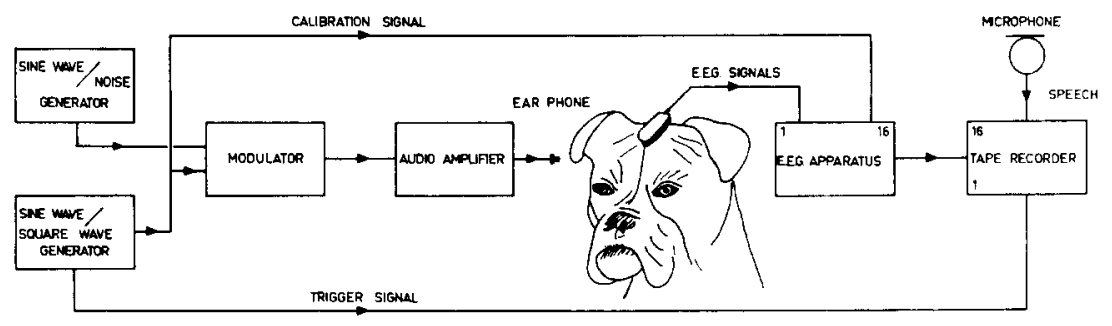

Fig. 1

Block diagram of the stimulating and recording arrangement.

the modulating signal were fed to a modulator in which the depth of modulation was set. The modulated carrier was then amplified and fed to two earphones, which were placed at the entrances of the external auditory meati (Fig. 1 and Tielen et al. 1967*). An example of sine wave amplitude-modulated sound is presented in Fig. 3, $C$.

\section{Periodic tone burst arrangement}

The tone, a sine wave of $4000 \mathrm{c} / \mathrm{sec}$, was modulated by a periodic square wave at a modulation depth of $100 \%$.

The sound level of the carrier, here called average intensity, was measured with a sound level meter (Bruël and Kjaer, type 2203), in the air at a distance of $1 \mathrm{~cm}$ from the opening of the earphones. The intensity is expressed in $\mathrm{dB}$. The reference sound pressure level, $0 \mathrm{~dB}$, is : $2 \cdot 10^{-4} \mu \mathrm{bar}$. Over the frequency range of $3200-5000 \mathrm{c} / \mathrm{sec}$ the intensity of the sound was constant within $\pm 2 \mathrm{~dB}$.

\section{Experimental conditions}

During the experiments the dog was alert and lying or sitting on a couch. The stimuli were presented during periods when the dog was quiet.

\section{Recording}

The derivations, in the following noted as E1, E2 ..., were against a common reference electrode consisting of a stainless steel pin in the frontal skull.

The recording (Fig. 1) was carried out by means of an EEG apparatus (Offner R-type) and a tape recorder (EMI). To the EEG apparatus were fed 15 EEG derivations and 1 signal to

* Report available on request from the Institute of Medical Physics, Utrecht, The Netherlands. indicate the modulation. This signal passed through the entire recording system and was used as calibration signal. To the tape recorder were also fed a trigger signal with a fixed relation to the modulating signal and a spoken commentary on the dog's behaviour.

\section{Analysis}

(1) The evoked responses were averaged by means of an average response computer CAT 400B (Mnemotron). Usually $1000-4000$ samples were added. The averaged responses were plotted by means of an X-Y recorder. (2) Harmonic analysis: three EEG signals and the calibration signal were averaged simultaneously so that 100 addresses corresponded to one period of the modulating signal. An analogue computer was programmed to perform harmonic analysis of the averaged signals, one at a time. For each averaged signal the amplitude, $A_{n}$, and phase angle, $\phi_{\mathrm{n}}$, of the first five harmonics were computed and printed out (formula 1).

\section{Amplitude and phase/frequency plots}

These plots were made for the first two harmonics. The modulating signal, a pure sine wave, was also analysed by the computer and in this case, of course, only the fundamental component was significant. Its amplitude, A, was then equivalent to the peak-to-peak amplitude and so was directly measurable in $\mu \mathrm{V}$. All amplitudes $\left(A_{n}\right)$ of the harmonics of the other signals were converted to $\mu \mathrm{V}$, using $\mathrm{A}$ as calibration.

The phase angles $\left(\phi_{1}\right)$ of the fundamental components at the various modulation frequencies were plotted against frequency on a linear scale. For the second harmonics the phase angle $\left(\phi_{2}\right)$ was converted to fundamental degrees. The

Electroenceph. clin. Neurophysiol., 1969, 26: 381-394 
signal was expressed then as follows:

$$
S(t)=\frac{1}{2} A_{0}+\Sigma A_{n} \sin n\left[\omega_{1} t-\left(\phi_{n} / n\right)\right]
$$

$\mathrm{n}=1,2$, so that $\phi_{\mathrm{n}} / \mathrm{n}$ was plotted against the fundamental frequency $\omega_{1}$.

The phase angle measured, considered as a
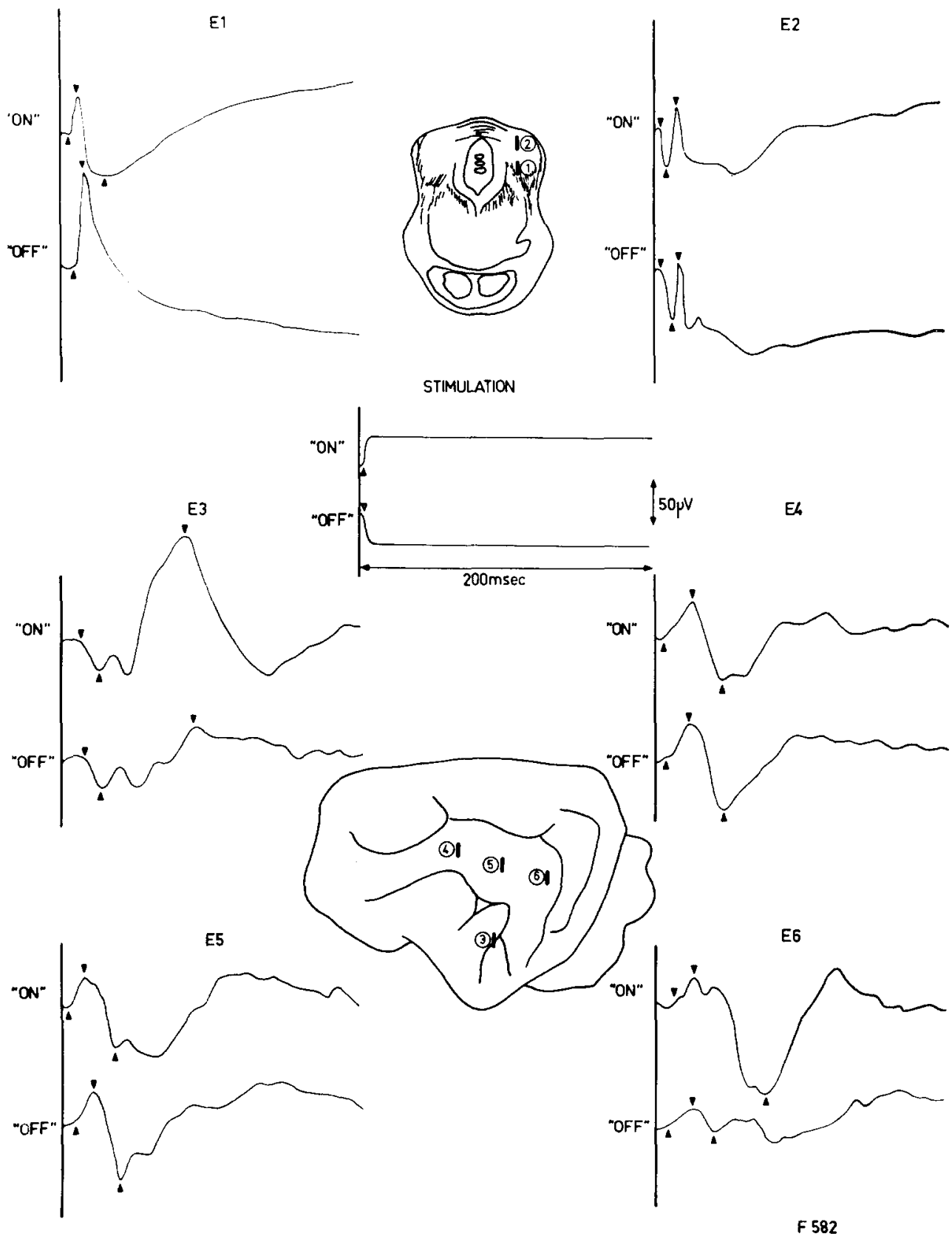

Fig. 2

Average evoked responses to the beginning ("on") and the end ("off") of periodic tone bursts recorded from inferior colliculus (E1, E2) and auditory cortex (E3, E4, E5 and E6). Tone frequency: $4000 \mathrm{c} / \mathrm{sec}$; intensity: $80 \mathrm{~dB}$; repetition rate: one tone burst every $2 \mathrm{sec}$. The marks in the curves are the measuring points for the latencies of the different parts of the responses (text). In all figures an upward deflection indicates negativity of the intracerebral electrode in relation to the common frontal reference electrode. 
phase difference between the modulating signal and the output, lay between $0^{\circ}$ and $360^{\circ}$. But since in our results the phase angle increased with frequency it was decided to add $360^{\circ}$ every time the phase went over $360^{\circ}$ with increase of frequency. For example: in Fig. 4 it is seen that the phase angle of the fundamental component $\phi_{1}$ at $\mathrm{E} 1$ increased with frequency from $10 \mathrm{c} / \mathrm{sec}$ to $30 \mathrm{c} / \mathrm{sec}$. At $30 \mathrm{c} / \mathrm{sec}$ the phase was $310^{\circ}$ and at $40 \mathrm{c} / \mathrm{sec}$ it was $40^{\circ}$. To obtain a continuous phase characteristic $360^{\circ}$ were added and the value $400^{\circ}$ was plotted. The same procedure was applied in all similar cases.

In the text, amplitude and phase of the fundamental component are abbreviated to "fundamental amplitude" and "fundamental phase". The same is done for the other harmonics. The plots of amplitude or phase against modulation frequency are abbreviated in this report to "amplitude" and "phase characteristics".

\section{RESULTS}

Responses evoked by periodic tone bursts

To enable comparison of the responses to sine wave-modulated sound with responses evoked by a more conventional form of auditory stimulation, one series of experiments was carried out with periodic tone bursts at an intensity of $80 \mathrm{~dB}$. The rise- and fall-time of the bursts were $5 \mathrm{msec}$, the tone frequency $4000 \mathrm{c} / \mathrm{sec}$ and the burst duration $500 \mathrm{msec}$. One burst was presented every $2 \mathrm{sec}$. In Fig. 2 the averages of 100 evoked responses to the beginning and the end of the tone bursts are shown, side by side.

At each electrode the responses evoked by the beginning ("on") and the end ("off") of the bursts started with deflections at the same polarity. The first peak amplitudes were of the same order of magnitude except at El where the "off" initial response had twice the amplitude of the "on" response. The later components of both evoked responses were similar at E4 and E5 and differed considerably at the other electrodes. In Table I the latencies and amplitudes of the first negative and the first positive peaks of "on" and "off" responses are summarized.

\section{Evoked responses to sinusoidally amplitude- modulated sound}

In the primary EEG the evoked responses were readily observable at the inferior colliculus

TABLE I

Responses evoked by tone bursts

\begin{tabular}{|c|c|c|c|c|c|c|}
\hline \multicolumn{7}{|c|}{ A. Latencies in msec } \\
\hline \multirow[b]{2}{*}{ Electr. } & \multicolumn{3}{|c|}{ "on" response } & \multicolumn{3}{|c|}{ "off" response } \\
\hline & Onset & $\begin{array}{c}\text { 1st neg. } \\
\text { peak }\end{array}$ & $\begin{array}{c}\text { 1st pos. } \\
\text { peak }\end{array}$ & Onset & $\begin{array}{l}\text { 1st neg. } \\
\text { peak }\end{array}$ & $\begin{array}{c}1 \text { st pos. } \\
\text { peak }\end{array}$ \\
\hline El & 8 & 11 & 28 & 7 & 12.5 & \\
\hline $\mathrm{E} 2$ & 5 & 14 & 8 & 4.5 & 13 & 8 \\
\hline E3 & 12.5 & 88 & 26 & 14 & 85 & 26 \\
\hline E4 & 11 & 28 & 44 & 11 & 21 & 45 \\
\hline E5 & 9 & 17 & 36 & 10 & 19 & 37 \\
\hline E6 & 11 & 28 & 74 & 8 & 23 & 36 \\
\hline
\end{tabular}

\section{B. Amplitudes in $\mu V$}

\begin{tabular}{lcccc}
\hline & $\begin{array}{c}\text { 1st neg. } \\
\text { peak }\end{array}$ & $\begin{array}{c}\text { 1st pos. } \\
\text { peak }\end{array}$ & $\begin{array}{c}\text { 1st neg. } \\
\text { peak }\end{array}$ & $\begin{array}{c}\text { 1st pos. } \\
\text { peak }\end{array}$ \\
\hline E1 & 90 & 106 & 160 & 160 \\
E2 & 25 & 49 & 18 & 60 \\
E3 & 120 & 35 & 42 & 21 \\
E4 & 42 & 53 & 39 & 60 \\
E5 & 35 & 56 & 32 & 60 \\
E6 & 25 & 110 & 17 & 5 \\
\hline
\end{tabular}



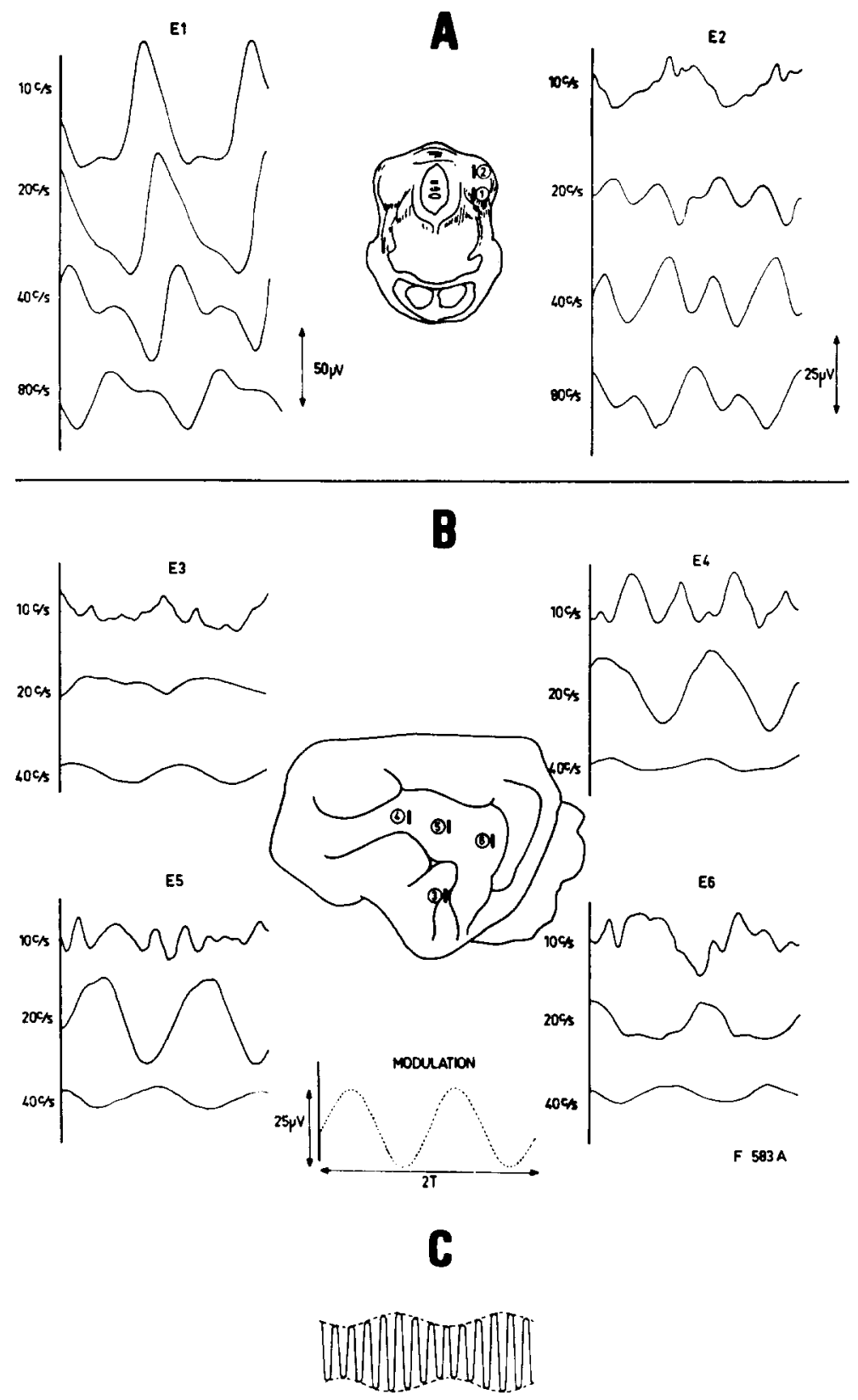

Fig. 3

Examples of average evoked responses to sinusoidally amplitude-modulated sound (SAMS) with $4000 \mathrm{c} / \mathrm{sec}$ carrier, $80 \%$ modulation depth, $74 \mathrm{~dB}$ intensity and several modulation frequencies. In $A$ the responses recorded from inferior colliculus are shown and in $B$ the responses from auditory cortex. The analysis time was always $2 \mathrm{~T}$, indicating that it changed with modulation frequency. ( $\mathrm{T}=1 / \mathrm{f} ; \mathrm{f}$ is the modulation frequency). In $C$ a sample of sine wave amplitude-modulated sound with sine wave carrier and $20 \%$ modulation depth. Two periods of the modulating signal are shown.

(E1) but difficult to detect at the auditory cortex electrodes.

Because the wave forms of the responses were usually complex and difficult to describe in quantitative terms, a form of signal analysis was applied; i.e., harmonic analysis (see Methods). 
In almost all cases the averaged responses could be described to a high degree of accuracy by fundamental and second harmonic components only. Hence, in the following the description of our results will be limited to these two components.

Most experiments with the same stimulus parameters were repeated 3 times in sessions of 2 min duration, several weeks apart. In a few cases, only one session of experiments per stimulus parameter was carried out. The amplitudes and the phases of the fundamental and second harmonic components were computed from the average responses obtained at the three independent sessions. The means and the standard deviations of these three amplitudes and phases were calculated.

\section{A. Influence of modulation frequency}

The main part of the experiments was carried out with the following stimulation parameters: modulation depth $80 \%$; carrier frequency $4000 \mathrm{c} / \mathrm{sec}$; average intensity $74 \mathrm{~dB}$. The modulation frequencies applied were 10, 15, 20, 30, 40, 60 and $80 \mathrm{c} / \mathrm{sec}$.

Inferior colliculus. In Fig. 3, $A$ examples of average responses at the two inferior colliculus electrodes E1 and E2 to several frequencies are shown. In Fig. 4 their mean fundamental and second harmonic amplitudes and phases and their standard deviations are plotted. At El the mean fundamental amplitudes were between $95 \mu \mathrm{V}$ at $20 \mathrm{c} / \mathrm{sec}$ and $65 \mu \mathrm{V}$ at $80 \mathrm{c} / \mathrm{sec}$. At the same electrode the mean harmonic amplitudes were always smaller than the fundamental ones. A clear peak in the amplitude characteristics could not be discerned at this electrode. In Fig. 4 it is seen that the phase differences of the fundamental component $\phi_{1}$ at E1 and E2 increase with frequency. The slope of the phase characteristic (in the following called "phase slope") changes with frequency; this is especially noticeable at El where the phase slopes from 10 to $20 \mathrm{c} / \mathrm{sec}$ and 30 to $60 \mathrm{c} / \mathrm{sec}$ are steeper than those from 20 to $30 \mathrm{c} / \mathrm{sec}$.

Auditory cortex. Examples of average responses obtained at the 4 cortical electrodes are presented in Fig. 3, $B$. In Fig. 5 the means of the amplitudes and the phases in relation to the modulation frequencies are plotted. From this
E1
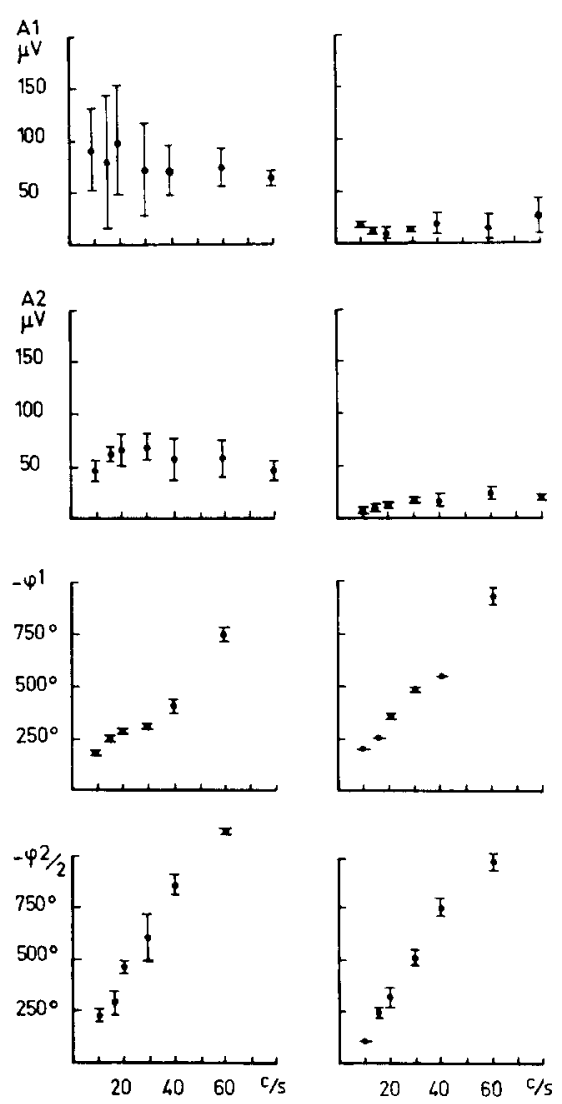

F580 A

Fig. 4

Amplitude and phase characteristics of the fundamental and second harmonic components of the average evoked responses to SAMS (for stimulating conditions, see text) recorded from the inferior colliculus (EI and E2). The horizontal axis indicates the modulation frequency and the vertical axis the fundamental amplitude $\mathrm{Al}$, second harmonic amplitude A2, fundamental phase $\phi_{1}$ and second harmonic phase $\phi_{2} / 2$ (in fundamental degrees, see text). The dots are means calculated from 3 observations and the lines through the dots indicate the standard deviations.

figure it can be seen that E4 and E5 presented the largest fundamental amplitudes of the cortical electrodes. At these two locations the mean fundamental amplitudes were largest in the frequency range from 15 to $30 \mathrm{c} / \mathrm{sec}$. The second harmonic amplitudes were small, $4-6 \mu \mathrm{V}$ being the maximum, and showed considerable variability. At $60 \mathrm{c} / \mathrm{sec}$ the amplitudes were negligible. Generally, the phases increased linearly with 

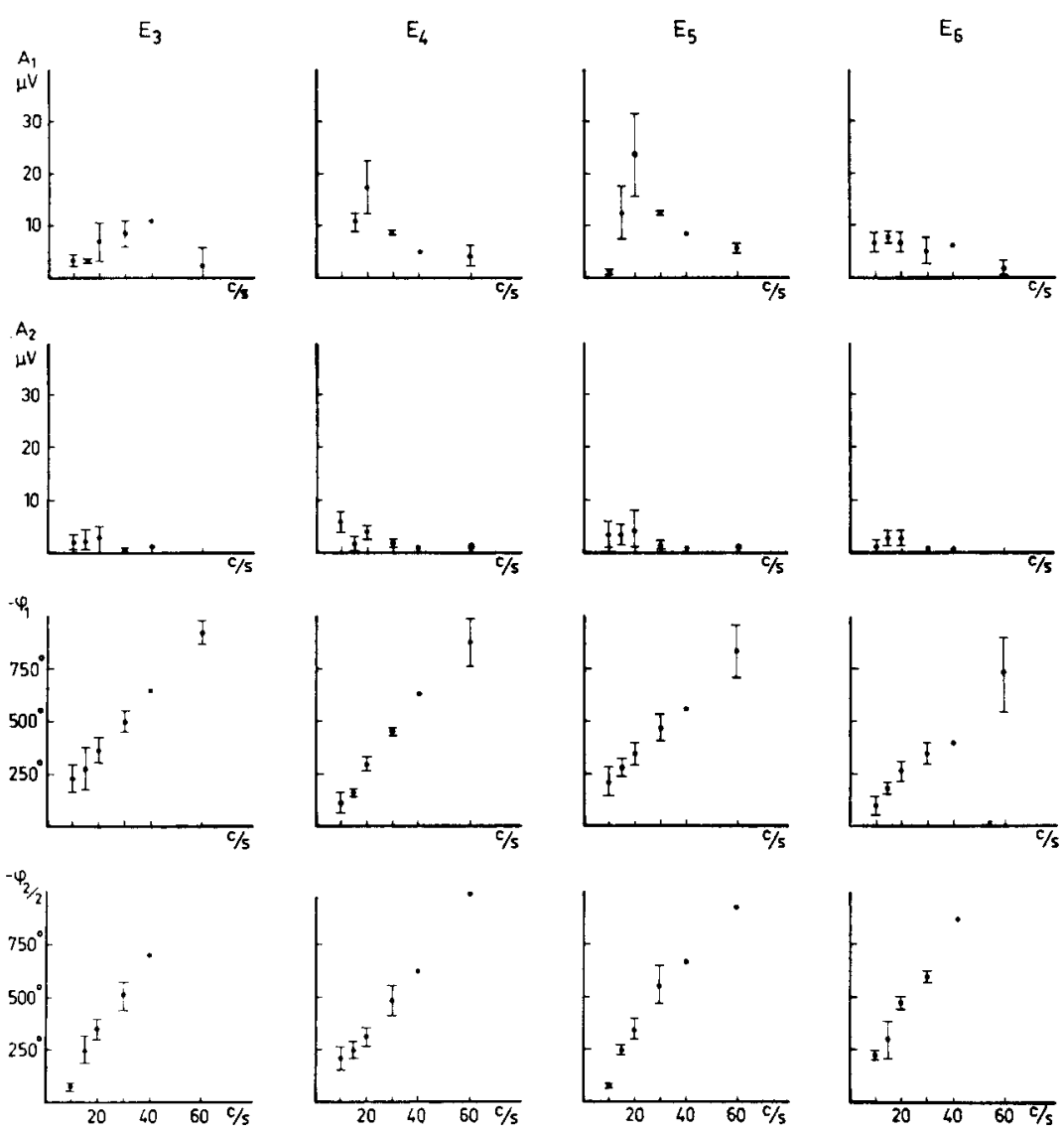

Fig. 5

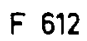

Amplitude and phase characteristics of average evoked responses to SAMS recorded from the cortical electrodes (legend of Fig. 4). Note that at $40 \mathrm{c} / \mathrm{sec}$ only one observation was made.

frequency, in the range investigated.

A few series of experiments were carried out for investigating the influence of some other stimulation parameters on the amplitude characteristic. One series of experiments was carried out with the same parameters but at an average intensity of $62 \mathrm{~dB}$. Only the cortical electrodes were studied; the amplitudes and phases of the average responses did not show appreciable differences in relation to those found at $74 \mathrm{~dB}$.

A second series of experiments was performed at the smallest modulation depth compatible with an adequate evaluation of the average response. This modulation depth was $5 \%$ for the inferior colliculus and $10 \%$ for the auditory cortex. The average intensity was again $74 \mathrm{~dB}$ and the carrier frequency $4000 \mathrm{c} / \mathrm{sec}$. In this series the responses were smaller at all electrodes and at all frequencies than those at $80 \%$ modulation depth. In the inferior colliculus the harmonic amplitudes were 10-20 times smaller at all modulation frequencies, and the amplitude characteristic at $5 \%$ was almost parallel to that at $80 \%$. In the auditory cortex, on the contrary, no such parallellism was observed. The decrease of the response amplitude from $80 \%$ to $10 \%$ modulation depth was more marked in the modulation frequency range from 15 to $30 \mathrm{c} / \mathrm{sec}$ than at other frequencies.

The phase characteristics at the small modulation depths were similar at all electrodes to those at $80 \%$, but the steepness of the phase slope increased by a factor of approximately two.

In a third series of experiments the average 
intensity was kept at $74 \mathrm{~dB}$ and the modulation depth at $80 \%$ but the carrier was changed to band-limited noise with bandwidth 3200-5000 $\mathrm{c} / \mathrm{sec}$. This change of carrier caused considerable modification of form and amplitude of the responses. In the inferior colliculus the fundamental amplitudes at both electrodes were larger with this carrier than with $4000 \mathrm{c} / \mathrm{sec}$, especially at the modulation frequencies 40 and $80 \mathrm{c} / \mathrm{sec}$. The harmonic analysis of the responses showed also a marked increase of the amplitude of higher harmonics, e.g., 3rd-4th-5th harmonics, in
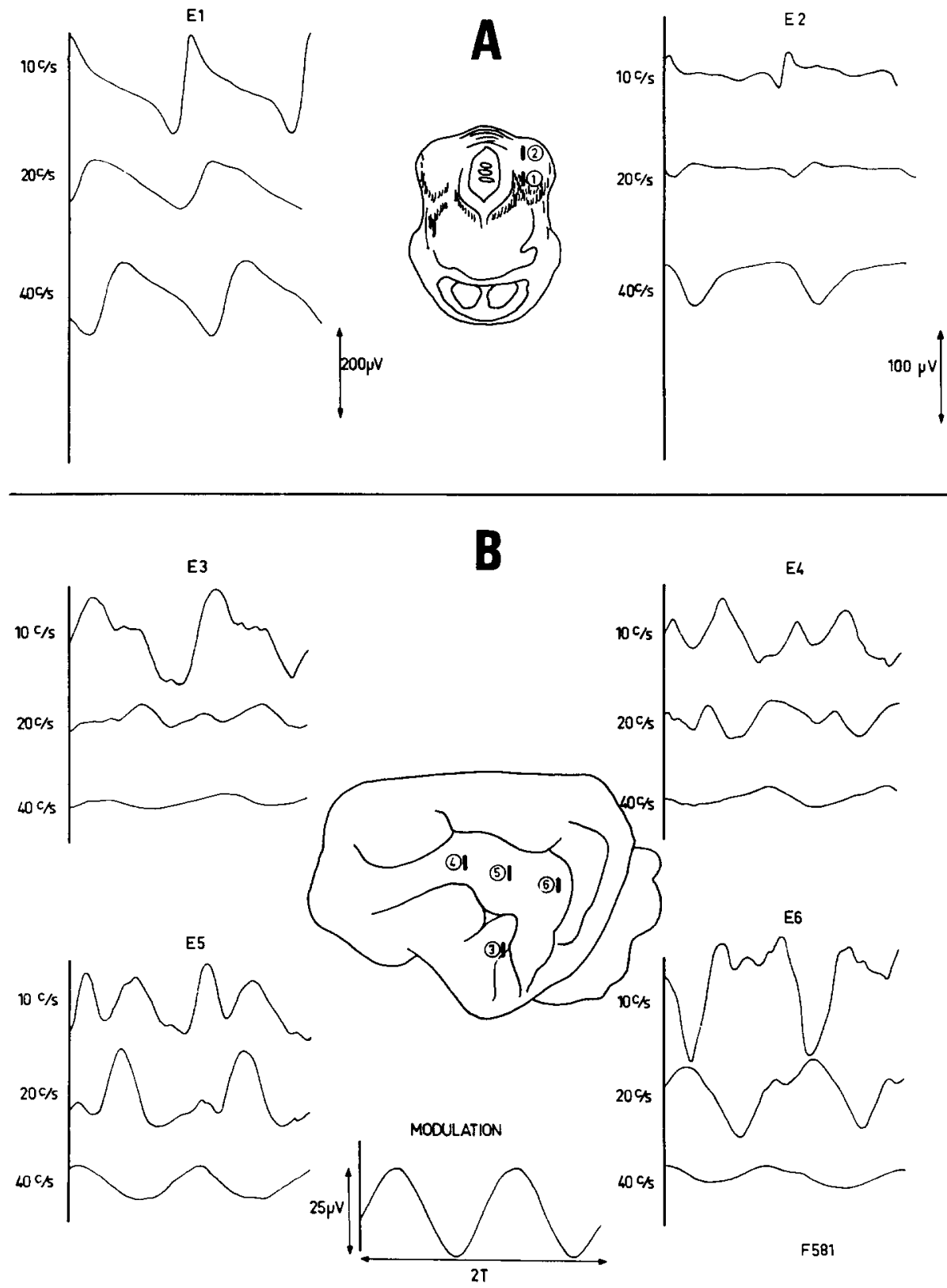

Fig. 6

Examples of average evoked responses to SAMS at several modulation frequencies but with bandlimited noise $(3200-5000 \mathrm{c} / \mathrm{sec})$ as carrier. $A$ : inferior colliculus; $B$ : auditory cortex. 
relation to those observed with a $4000 \mathrm{c} / \mathrm{sec}$ carrier. The auditory cortex responses did not show such marked changes in wave form and amplitude. However, the harmonic analysis presented an increase of the fundamental and second harmonic amplitudes in the $10-15 \mathrm{c} / \mathrm{sec}$ frequency range. Some examples of the evoked averaged responses are shown in Fig. 6.

B. Influence of modulation depth

The influence of modulation depth on the average evoked responses was studied with the
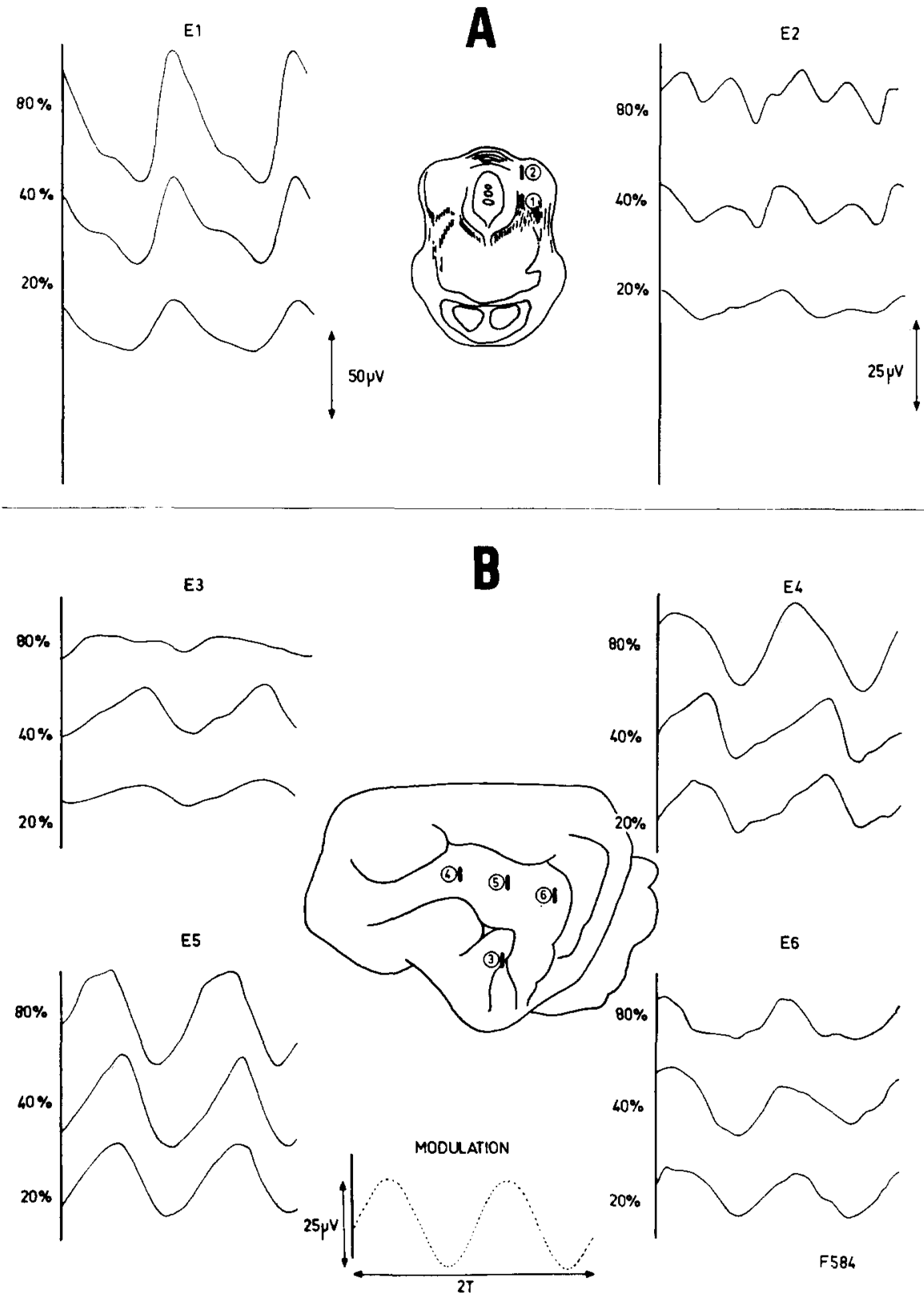

Fig. 7

Average evoked responses to SAMS at different modulation depths. The modulation frequency was kept constant at $20 \mathrm{c} / \mathrm{sec}$. In $A$ are shown responses recorded from inferior colliculus and in $B$ from auditory cortex areas. 
following stimulus parameters: (a) carrier 4000 $\mathrm{c} / \mathrm{sec}$; (b) modulation frequency $20 \mathrm{c} / \mathrm{sec}$; (c) average intensity $74 \mathrm{~dB}$. Three separate sessions per modulation depth were carried out. From the results, the mean amplitudes and standard deviations were calculated and plotted. The modulation frequency of $20 \mathrm{c} / \mathrm{sec}$ was chosen because at this frequency the fundamental amplitudes were large at E4 and E5 and clearly detectable at E3 and E6.

Change of modulation depth caused change of amplitude and wave form of the average evoked responses at all electrodes. Some examples of this effect are shown in Fig. 7. From the harmonic analysis of the responses it appeared (Fig. 8 and 9) that the changes concerned the amplitudes of the fundamental and second harmonic response components and to some extent also their phase relations to the modulating signal. The effects in the inferior colliculus and in the auditory cortex were as follows:

Inferior colliculus (Fig. 8). The mean amplitudes of the fundamental components at $\mathrm{E} 1$ and the second harmonic components at E1 and E2 increased almost linearly with the modulation depth. At E2 the fundamental amplitudes increased from 5 to $10 \%$ but showed no obvious further increase from 10 to $80 \%$. The mean phase differences between the modulating signal and the fundamental components showed some change with modulation depth. At E1 the phase difference was somewhat larger at $5 \%$ than at the other modulation depths. At E2, on the contrary, it was smallest at $5 \%$ and appeared to increase towards larger modulation depths. The mean phase difference between the modulating signal and the second harmonic components showed little change with modulation depth at both E1 and E2.

Auditory cortex (Fig. 9). At E4 and E5 the relation between the mean fundamental amplitude (A) and the modulation depth (m) was not linear, as at E1, but fitted well the function $\mathrm{A}=\mathrm{km}^{\mathrm{b}}$. For $\mathrm{E} 5 \mathrm{~b}=0.63$ and $\mathrm{k}=1.9$ and for $\mathrm{E} 4$ $b=0.68$ and $k=1$. In Fig. 9 it can also be seen that at E3 and E6 the mean amplitudes of the fundamental components increased with modulation depth from 5 to $40 \%$ but did not increase, or even decreased slightly, from $40 \%$ to $80 \%$. The amplitudes of the second harmonics were
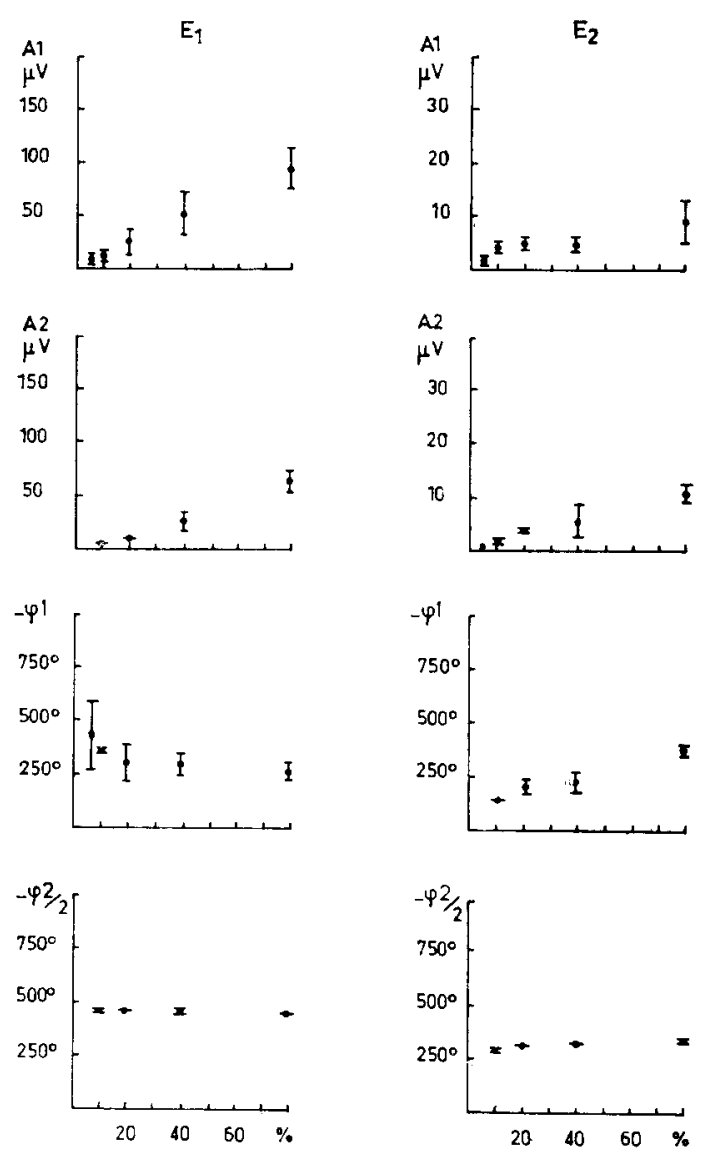

Fig. 8

F585 B

Amplitude and phase characteristics of fundamental (A1, $\left.\phi_{1}\right)$ and second harmonics $\left(\mathrm{A} 2, \phi_{2}\right.$ ) at different modulation depths, at a modulation frequency of $20 \mathrm{c} / \mathrm{sec}$ (inferior colliculus). The dots represent the means of 3 obsetvations and the lines through the dots indicate the standard deviations.

very small, at some parameters barely above noise level, and consequently these components were not considered further.

At all electrodes the phase difference between the modulating signal and the fundamental and second harmonic components had slightly larger values at $10 \%$ than at higher modulation depths. (Note: the data on $5 \%$ modulation depth are not included in this series because the responses were too small).

\section{DISCUSSION}

The experiments presented here show that it is possible to detect responses evoked by sinus- 
E3
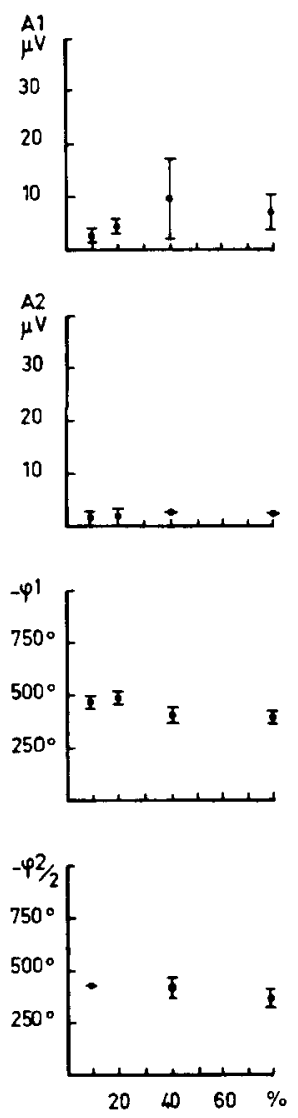

EL
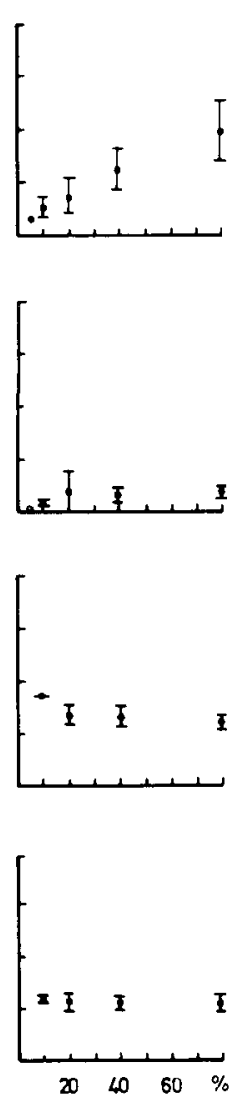

E5
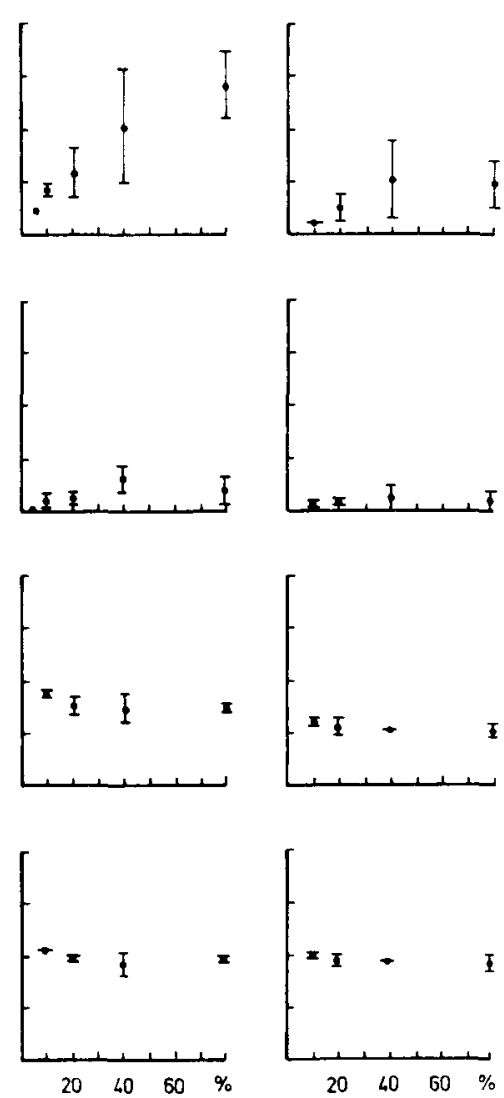

F579 A

Fig. 9

Similar to Fig. 8 but from auditory cortex.

oidally amplitude-modulated sound (SAMS) at the auditory cortex and at the inferior colliculus in unanaesthetized dogs. In our study a full investigation into the influence of all stimulus parameters has not been attempted. Indeed, the main interest has been the influence of modulation frequency in the range $10-80 \mathrm{c} / \mathrm{sec}$ and modulation depth from 5 to $80 \%$ at one of these frequencies. In addition, limited explorations have been carried out into the effects of changes of some of the other stimulus parameters: to small modulation depth, average intensity of $62 \mathrm{~dB}$ and a band-limited noise carrier.

The variability of the average evoked responses showed no particular trend over the course of the investigatory period-for instance no signs of habituation were noted-and thus the averages may be considered as reasonably representative.

Most of the average responses are not pure sine waves, but are distorted to a greater or lesser degree. The distortion is least in the responses from the cortical areas at modulation frequencies of $20 \mathrm{c} / \mathrm{sec}$ and higher. These responses present an almost sinusoidal wave form and thus are easily quantifiable (Fig. 3). However, for expression in quantitative terms of all the evoked responses some form of signal analysis is needed. Because of the above, a method based on analysis into sine waves seemed appropriate and consequently harmonic analysis was applied. This point of view was strengthened by the subsequent finding that the power of a good many of the electrical potentials was concentrated in the first 
two harmonic components. The identification in the responses of sine waves at frequencies related coherently with the modulating signals makes it possible to study the time-locked slow neural activity through these basic functions. In the following, amplitude and phase of the responses, particularly the fundamental components, will be discussed as functions of modulation frequency.

All phase characteristics show an increase of phase lag with frequency. In many cases the characteristics approximate a linear function. Characteristics such as these are encountered in transmission lines with a constant time delay. If our phase characteristics are regarded from this point of view an estimate of the delay between the modulating signal and the evoked response can be determined in the way described by van der Tweel and Verduyn Lunel (1965) for responses to sine wave modulated light.

The delay, in seconds, is equal to $\Delta \phi / \Delta f .360^{\circ}$, $\Delta \phi$ in degrees and $\Delta \mathrm{f}$ in $\mathrm{c} / \mathrm{sec}$. Thus, a physiological meaning is ascribed to the phase characteristic. The time delay so calculated is: for the anterior ectosylvian gyrus (E4) $43 \mathrm{msec}$, for the middle ectosylvian gyrus (E5) $34 \mathrm{msec}$, and for the posterior ectosylvian gyrus (E6) $35 \mathrm{msec}$. In these three areas the responses evoked by tone bursts show clear positive peaks with latencies of $44 \mathrm{msec}, 36 \mathrm{msec}$ and $74 \mathrm{msec}$ to the beginning and $45 \mathrm{msec}, 37 \mathrm{msec}$ and $36 \mathrm{msec}$ to the end of the tone burst (Table I). All but one of these values, therefore, have nearly the same magnitude as the corresponding time delays. In one other cortical area (posterior sylvian gyrus, E3), however, this close relationship is not evident, but in this area the late positive peak is also not distinguishable in the tone burst evoked response. The above seems to indicate that similar pathways are involved for the responses evoked by SAMS as for late response components evoked by transients. This may be related to the finding of Teas and Kiang (1964), who found that the early components of the click response almost disappeared during repetitive stimulation, even at comparatively low repetition rates, while the late components were still present. The same authors observed that the independence of the different components of the responses to transients "raises the issue of multiple projection systems to the classical auditory cortex". From our results it appears that the responses to SAMS with modulation frequency above $10 \mathrm{c} / \mathrm{sec}$ are transmitted mainly over the pathways with relatively long latencies, "slow pathways".

Some special attention may be devoted to the phase characteristics obtained from the inferior colliculus (E1). The phase characteristics in this structure diverge from a linear relation with frequency in such manner as if several time delays were contributing to the response at various frequencies. This finding may be related to the fact that the inferior colliculus electrode (E1) was situated partly inside the nucleus and partly made contact with external lemniscal fibres. Nevertheless, all these time delays are shorter than the cortical ones.

The amplitude characteristics of some areas of the auditory cortex and the inferior colliculus show marked differences. In the inferior colliculus the function is comparatively flat, decreasing only towards high modulation frequencies. A similar relation was found at one cortical location (posterior ectosylvian gyrus). Goldstein et al. (1959) also showed a flat characteristic in the frequency range from 10 to $40 \mathrm{c} / \mathrm{sec}$ for the cat's auditory cortex responses evoked by periodic noise bursts. In our experiments, at some cortical locations (anterior and middle ectosylvian gyrus), the relation between amplitude and frequency deviated from a flat characteristic, presenting a maximum in the range $15-30 \mathrm{c} / \mathrm{sec}$. Before an interpretation of this finding can be advanced, the responses in this frequency range will have to be investigated further, utilizing smaller frequency intervals.

Concerning the influence of low modulation depth $(5 \%$ for inferior colliculus and $10 \%$ for auditory cortex) on the amplitude characteristics it can be pointed out that at the inferior colliculus these characteristics are essentially the same as at $80 \%$ modulation depth but at a lower amplitude level. However, at some of the cortical areas this is not the case. At the anterior and medial ectosylvian gyrus the amplitudes were more affected in the frequency range $15-30 \mathrm{c} / \mathrm{sec}$ than at other frequencies. It is of importance to note that the amplitude modulation depth characteristics obtained from these areas show a power law relation between these two parameters, whereas the characteristics in the other auditory 
cortex areas are different. In these areas the response amplitudes do not increase with increasing modulation depth but remain the same after surpassing a given modulation depth. This phenomenon is similar to the "saturation" described by van der Tweel and Verduyn Lunel (1965) for responses to sinusoidally modulated light.

The influence of carrier frequency has not been extensively investigated but even the change from a sine wave carrier at $4000 \mathrm{c} / \mathrm{sec}$ to a band-limited noise $(3200-5000 \mathrm{c} / \mathrm{sec})$ leads to a modification of the responses and their distribution at the cortex. The data so far obtained are insufficient to draw general conclusions; more information with sine wave carriers at other frequencies and noise with other bandwidths is needed.

One of the main interests of investigating systems such as the auditory projection areas with periodic stimuli is that this form of stimulation emphasizes those rhythmic properties of the system which are also apparent in the "spontaneous" EEG. In connection with this it is interesting to remark that the frequency range at which the auditory cortex responds with the highest amplitude, is in the band of the beta rhythm $(15-24 \mathrm{c} / \mathrm{sec})$, which predominates in the ectosylvian gyrus in behavioural situations in which the animal is alert but shows no great interest in the ambient situation (Storm van Leeuwen et al. 1967), as indeed occurred also during stimulation.

\section{SUMMARY}

1. Responses evoked by sinusoidally amplitude-modulated sound in unanaesthetized dogs have been recorded from inferior colliculus and from auditory cortex structures by means of chronically indwelling stainless steel wire electrodes.

2. Harmonic analysis of the average responses demonstrated that the energy of most of the responses was concentrated in components at fundamental and second harmonic frequencies.

3. The influence of various stimulus parameters was investigated, in particular the effect of variation of modulation frequency between 10 and $80 \mathrm{c} / \mathrm{sec}$.
4. The amplitude/frequency characteristics of the fundamental components obtained from the inferior colliculus were almost flat, with a slight amplitude decrease at frequencies above $60 \mathrm{c} / \mathrm{sec}$. In some of the cortical areas the characteristics showed a maximum of amplitude at modulation frequencies between 15 and $30 \mathrm{c} / \mathrm{sec}$.

5. The phase/frequency characteristics showed a lag of phase with modulation frequency. From this phase lag delay times were calculated. Those at the inferior colliculus were shorter than those at the auditory cortex. At the latter structure the calculated delay times corresponded closely with latencies of the first positive deflection of responses evoked in these same structures by tone bursts.

6. The amplitude modulation depth characteristics showed that the amplitudes of the responses were influenced by modulation depth. At the inferior colliculus an almost linear relation appeared to exist between modulation depth and response amplitudes.

In the auditory cortex more complex relations between modulation depth and amplitude occurred. "Saturation" phenomena were observed in two cortical areas.

7. Restricted investigations into the effects of the composition of the carrier signal revealed that change of carrier signal from sine wave at 4000 $\mathrm{c} / \mathrm{sec}$ to band-limited noise at $3200-5000 \mathrm{c} / \mathrm{sec}$ caused change of the response amplitude distribution over the auditory cortex. Decrease of average intensity to $62 \mathrm{~dB}$ produced no change.

\section{RÉSUMÉ}

RÉPONSES ÉVOQUÉES À DES SONS MODULÉS SINUSOÏDALEMENT CHEZ DES CHIENS NON-ANESTHÉSIÉS

1. Les réponses évoquées par des sons d'amplitude modulée sinusoïdalement ont été enregistrées chez des chiens non-anesthésiés au niveau du colliculus inférieur et de structures corticales auditives au moyen d'électrodes d'acier inoxydable chroniquement implantées.

2. L'analyse harmonique des réponses moyennes montre que l'énergie de la plupart des réponses se concentre en des composantes de fréquence fondamentale et harmonique seconde.

3. L'influence de divers paramètres de stimulation est explorée, en particulier l'effet de

Electroenceph. clin. Neurophysiol., 1969, 26: 381-394 
la variation de la fréquence de modulation entre 10 et $80 \mathrm{c} / \mathrm{sec}$.

-4. La courbe d'amplitude en fonction de la fréquence des composantes fondamentales obtenues au niveau du colliculus inférieur est presque plate; on note une légère diminution d'amplitude de cette courbe pour des fréquences supérieures à $60 \mathrm{c} / \mathrm{sec}$. Dans certaines aires corticales un maximum d'amplitude s'observe pour des fréquences de modulation comprise entre 15 et $30 \mathrm{c} / \mathrm{sec}$.

5. La courbe des phases en fonction de la fréquence montre un retard de phase associé à la fréquence de modulation. A partir de ce retard de phase des délais ont été calculés. Ceux-ci sont plus courts pour le colliculus inférieur que pour le cortex auditif. Pour cette dernière structure, les délais calculés correspondent étroitement aux latences de la première déflection positive des réponses évoquées au niveau des mêmes structures par des séries de sons.

6. La courbe d'amplitude en fonction de la profondeur de modulation montre que les amplitudes des réponses sont influencées par la profondeur de modulation. Au niveau du colliculus inférieur semble exister une relation presque linéaire entre la profondeur de modulation et les amplitudes des réponses. Dans le cortex auditif, les relations entre profondeur de modulation et amplitude sont plus complexes. Des phénomènes de "saturation" ont été observés dans deux aires corticales.
7. Quelques investigations sur les effets de la composition de la porteuse révèlent qu'une modification de la composition d'une porteuse sinusoïdale à $4000 \mathrm{c} / \mathrm{sec}$ en bruit limité à la bande de $3200-5000 \mathrm{c} / \mathrm{sec}$ détermine un changement de distribution de l'amplitude des réponses sur le cortex auditif. Une diminution d'intensité moyenne jusqu'à $62 \mathrm{~dB}$ ne produit aucun changement.

\section{REFERENCES}

BickFord, R. G., JACOBSON, J. L. and CODY, T. R. Nature of average evoked potentials to sound and other stimuli in man. Ann. N.Y. Acad. Sci., 1964, 112: 204-217.

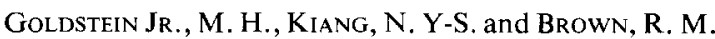
Responses of the auditory cortex to repetitive acoustic stimuli. J. acoust. Soc. Amer., 1959, 31: 356-364.

Rapin, I., Schimmel, H. and Tourk, L. M. Evoked responses to clicks and tones of varying intensity in waking adults. Electroenceph. clin. Neurophysiol., 1966, 21: 335-344.

Storm van Leeuwen, W., Kamp, A., Kok, M. L., Quartel, F. W. De, Lopes da Silva, F. H. et Tielen, A. M. Relations entre les activités électriques cérébrales du chien, son comportement et sa direction d'attention. Actualités neurophysiol., 1967, 7: 167-186.

TEAS, D. C. and KIANG, N. Y-S. Evoked responses from the auditory cortex. Exp. Neurol., 1964, 10: 91-119.

Tweel, L. H. VAN der and Verduyn Lunel, H. F. E. Human visual responses to sinusoidally modulated light. Electroenceph. clin. Neurophysiol., 1965, 18: 587-598.

Whitfield, I. C. Abstr. XIX Int. physiol. Congr., 1953: 885.

Whitfield, I. C. The electrical responses of the unanaesthetized auditory cortex in the intact cat. Electroenceph. clin. Neurophysiol., 1957, 3: 35-42.

Reference: Tielen, A. M., Kamp, A., Lopes da Silva, F. H., Reneau, J. P. and Storm van Leeuwen, W. Evoked responses to sinusoidally modulated sound in unanaesthetized dogs. Electroenceph. clin. Neurophysiol., 1969, $26: 381-394$. 